\title{
The Study of Application-oriented Profession Quality Evaluation Index System
}

\author{
Fenping Wang \\ School of Science, Jinling Institute of Technology, Nanjing, China
}

\section{Email address:}

wfp@jit.edu.cn

\section{To cite this article:}

Fenping Wang. The Study of Application-oriented Profession Quality Evaluation Index System. Higher Education Research. Vol. 6, No. 5, 2021, pp. 126-131. doi: 10.11648/j.her.20210605.15

Received: August 31, 2021; Accepted: September 14, 2021; Published: September 23, 2021

\begin{abstract}
Application-oriented professions are developing rapidly, but the evaluation criteria for the quality of application-oriented professions are rare, By referring to the quality evaluation and Accreditation standards of science and engineering majors in various countries, the quality evaluation standards of science and engineering majors have been formulated, and the weights of the evaluation standards have been determined through questionnaire surveys. Three levels of indicators, the first level indicators include Curriculum construction, Professional skills training and competency, Faculty and Staff Resources, Employer cooperation. Each first-level indicator contains several second-level indicators, a total of 13 second-level indicators, each second-level indicator contains several third-level indicators, a total of 38 third-level indicators. The Index System Embodies the Student-Centered and Pragmatic Educational Concepts, It reflects the requirements for the professional skills of graduates of applied majors, and also reflects the requirements for training in cooperation with employers, It also reflects the requirements for the innovative ability of undergraduate graduates, requiring applied universities to pay attention to their social responsibilities. Applied engineering technology majors lack specific curriculum guidance, and it is necessary to strengthen school-enterprise cooperation and increase dual-qualified teachers with practical experience in engineering technology.
\end{abstract}

Keywords: Applied Bachelor Degree, Professional Quality, Evaluation Index

\section{Introduction}

China has been building applied majors on a large scale since 2004, At the same time, Engineering education research (EER) in the world has developed rapidly, and doctorate degrees in engineering has also grown rapidly, More engineering education, Even more engineering education research department has even been established in America, Europe and china. After 2005 Ministers' Conference in Bergen, Quality assurance (QA) of higher education (HE) has gradually become a major concern of the "Bologna Process". ENAEE (The European Network for Accreditation of Engineering Education) was founded on 8 February 2006, Members of ENAEE interest in the quality of engineering professionals. China has become a full member of the Washington Accord In 2016. At present, there are relatively few researches specifically on appraisal standards of applied professions. How to evaluate the quality of science and engineering education? It is necessary to construct an evaluation index system specially used to evaluate the quality of applied professions.

\section{Method}

\subsection{Overall Design}

A quantitative method of analysis be used to analyse this valuable data, Using comprehensive questionnaires for assessments. Refer to European Qualifications Framework (EQF), International Labour Office (ILO)'s quality assessment methodology, Evaluation Office International Engineering Alliance (IEA), Board for Engineering and Technology (ABET), ENAEE and the EUR-ACE (EURopean-Acredited Engineer) Framework Standards (EAFS), Applied majors are called Professional Higher Education (PHE) in some European countries. The PHExcel Consortium in Scotland regards even Accreditation standards as professional quality evaluation tools. Draw conclusions 
from these documents. Preliminarily determine the quality evaluation indicators, and compile questionnaires based on the indicators. The use of questionnaires or checklists that include all the relevant items leads to a better QA result. Not only does it ensure that every aspect of the research is reviewed, but it promotes the improvement of overall quality through the correction of specific issues. Using Delphi method and AHP for the Research, Some Study on the Improvement of Quality With a Fuzzy Analysis on Quality Evaluation Index through Combine this index system with the fuzzy [1]. European Parliament's document (Bernd Wächter, Maria Kelo, 2020) about Study examines separately two different quality approaches, quality assurance and rankings [2]. On the basis of this evaluation index system, Professional quality evaluation can be done using a comprehensive evaluation model with fuzzy matrix as a tool.

\subsection{Participants}

The survey population includes 12 human resources administrators from 12 companies, 11 doctors and doctoral supervisors from 4 science and engineering colleges, 3 business managers, and 82 science and engineering graduates of applied majors who Graduated over 5 years. These respondents are asked to give weight to each indicator in the indicator system, Use analytic hierarchy process (AHP) to process data to get the weight of each indicator.

\section{Result}

\subsection{Develop Indicators}

In the basis According to existing research conclusions and evaluation standards of the applied baccalaureate program which are focused on obtaining theoretical training and the acquisition of practical skills in the production. It is reflected in changing of hours of the applied bachelor degree practical part of concrete direction. Moreover, the practical part of the program, including laboratory and practical classes, educational and industrial practice, is not less than half of the total time allotted for training. The indicator system includes 4 first-level indicators: A, B, C, D, 13 second-level indicators, and 38 third-level indicators,

A: Curriculum construction.

A1: Practical courses integrating production and Education.

A11: School-enterprise cooperative learning activities.

A12: In-school training activities.

A13: Industry participation in curriculum construction.

A2: STEM course Construction.

A21: The related technology Integration courses of this major.

A22: Combination of curriculum knowledge with production process and social practical activities.

A23: Course knowledge combined with other related professional knowledge.

A3: Integration of basic courses, main courses and core courses.
A31: Collective preparation courses by teachers of basic and professional courses.

A32: Teachers of basic courses and specialized courses jointly compile textbooks.

B: Professional ability training.

B1: the curriculum system focuses on skill training.

B11: Combination of teaching Process and production practice process.

B12: Combination of course content and industry Standards.

B13: Combination of course content and Employment standards.

B14: Integration of professional skills with experiments and internships.

B2: technology transfer, Cultivation of entrepreneurial ability and innovative Spirit.

B21: Regularly carry out application-oriented professional innovation activities.

B22: Specially offer training Courses for innovation and innovation ability.

B23: The school sets up a reward mechanism for industry University cooperation to encourage students to Innovate.

B24: The number of students' patents and other Achievements and their Promotion.

B25: Carry out technology Development cooperation projects with employers

B26: A technology Transformation and incubation center is built in the school or in cooperation with outside the school

B3: Practical ability training.

B31: Carry out hands-on practical skills qualification Assessment

B32: Carry out various hands-on practical ability competitions.

C: Faculty and Staff Resources Prospect.

C1: Existing Complete faculty Structure.

C11: Teachers with work experience in industrial units Account for $30 \%$.

C12: A complete faculty of Subjects related to the Profession.

C13: International teacher exchange.

$\mathrm{C} 2$ : The aim of future teacher team Construction.

C21: Professional teachers go to industrial units to exchange and study every year.

C22: Regular exchanges between basic course teachers and professional course teachers.

C23: Encourage Professional teacher to Choose opportunities to stay in the factory for research.

C3: Teacher's academic level.

C31: The results of teachers' applied research can be promoted.

C32: The number and level of applied research projects that teachers have obtained.

D: Cooperate with Industry to cultivate students.

D1: Provide technology and training for the industry

D11: Provide general skills training in the industry.

D12: Provide cutting-edge and unpromoted new technology training. 
D2: Cultivate Human resources that meet the needs of the industry.

D21: Regularly investigate the human resource needs of employers.

D22: Set up a training base in the employer.

D23: Graduates obtain industry qualifications.

D3: Industry participateon in professional creation.

D31: Industry participation in Professional addition or cancelation activities.

D32: Industry participation Human resources training model design.

D33: Industry experts participate in professional Accreditation.

D4: Regularly research the employer's evaluation of graduates.

D41: Employer's evaluation of Graduates' skills.

D42: Employers' evaluation of graduates' professional spirit and professional ethics.

Table 1. Descriptive statistics of the professional bachelors Quality standard $(N=108)$.

\begin{tabular}{|c|c|c|c|c|c|}
\hline \multicolumn{2}{|c|}{ First level indicator } & \multicolumn{2}{|c|}{$\begin{array}{l}\text { Secondary level } \\
\text { indicator }\end{array}$} & \multicolumn{2}{|c|}{ Three level indicators } \\
\hline indicator & Weight & indicator & Weight & indicator & Weight \\
\hline \multirow{8}{*}{ A } & \multirow{8}{*}{0.25} & \multirow{3}{*}{ A1 } & \multirow{3}{*}{0.30} & A11 & 0.36 \\
\hline & & & & $\mathrm{A} 12$ & 0.40 \\
\hline & & & & A13 & 0.24 \\
\hline & & \multirow{3}{*}{$\mathrm{A} 2$} & \multirow{3}{*}{0.40} & $\mathrm{~A} 21$ & 0.40 \\
\hline & & & & $\mathrm{A} 22$ & 0.26 \\
\hline & & & & $\mathrm{A} 23$ & 0.24 \\
\hline & & \multirow{3}{*}{ A3 } & \multirow{3}{*}{0.30} & $\mathrm{~A} 31$ & 0.70 \\
\hline & & & & A32 & 0.30 \\
\hline \multirow{12}{*}{ B } & \multirow{12}{*}{0.30} & & & B11 & 0.34 \\
\hline & & \multirow{3}{*}{ B1 } & \multirow{3}{*}{0.40} & $\mathrm{~B} 12$ & 0.12 \\
\hline & & & & B13 & 0.18 \\
\hline & & & & B14 & 0.46 \\
\hline & & \multirow{6}{*}{ B2 } & \multirow{6}{*}{0.30} & B21 & 0.13 \\
\hline & & & & $\mathrm{B} 22$ & 0.26 \\
\hline & & & & B23 & 0.18 \\
\hline & & & & B24 & 0.13 \\
\hline & & & & B25 & 0.14 \\
\hline & & & & B26 & 0.16 \\
\hline & & \multirow{2}{*}{ B3 } & \multirow{3}{*}{0.30} & B31 & 0.60 \\
\hline & & & & B32 & 0.40 \\
\hline \multirow{8}{*}{$\mathrm{C}$} & \multirow{8}{*}{0.25} & \multirow{3}{*}{$\mathrm{C} 1$} & & $\mathrm{C} 11$ & 0.35 \\
\hline & & & \multirow[t]{2}{*}{0.40} & $\mathrm{C} 12$ & 0.45 \\
\hline & & & & $\mathrm{C} 13$ & 0.20 \\
\hline & & \multirow{3}{*}{$\mathrm{C} 2$} & \multirow{3}{*}{0.30} & $\mathrm{C} 21$ & 0.48 \\
\hline & & & & $\mathrm{C} 22$ & 0.20 \\
\hline & & & & $\mathrm{C} 23$ & 0.32 \\
\hline & & \multirow{2}{*}{$\mathrm{C} 3$} & & $\mathrm{C} 31$ & 0.37 \\
\hline & & & 0.30 & $\mathrm{C} 32$ & 0.63 \\
\hline & & D1 & 025 & D11 & 0.65 \\
\hline & & DI & 0.25 & D12 & 0.35 \\
\hline & & & & $\mathrm{D} 21$ & 0.42 \\
\hline & & D2 & 0.35 & $\mathrm{D} 22$ & 0.38 \\
\hline & & & & $\mathrm{D} 23$ & 0.20 \\
\hline D & 0.20 & & & $\mathrm{D} 31$ & 0.36 \\
\hline & & D3 & 0.25 & D32 & 0.45 \\
\hline & & & & D33 & 0.19 \\
\hline & & & & D41 & 0.62 \\
\hline & & D4 & 0.15 & D42 & 0.38 \\
\hline
\end{tabular}

\subsection{Determination of Evaluation Index Weight}

Each indicator should has its own weight, Inviteing applied professional field experts to assign weights to the designated applied professional quality evaluation indicators, and then use the analytic hierarchy process to obtain the weights of each indicator.

\subsection{Basic Steps to Use Evaluation Index System to Evaluate Professional Quality}

Combining this evaluation index system with the fuzzy comprehensive evaluation model can compare the quality differences of different applied disciplines. The specific method includes several steps. The first step is to score the experts of each indicator in the index system. The second step is to substitute the expert scores into the fuzzy comprehensive evaluation model to calculate the comprehensive quality score of each specialty; the third step, By comparing the comprehensive quality scores of different majors, the quality of each applied major can be measured according to the scores.

\section{Discussion}

\subsection{Curriculum Construction}

Discipline-Based STEM Education is considered an effective path, The Dicipline-based education research report of The National Research Council of USA ([NRC], 2012) synthesize empirical research on undergraduate teaching and learning in the science, exploring the extent to which this research currently influences undergraduate instruction, and identify the intellectual and material resources required to further develop DBER, describes the discipline-specific difficulties learners face and the specialized intellectual and instructional resources that can facilitate student understanding [3]. International course exchange is also an important channel to improve the level of engineering and technology education, Ivan Birch (2000) gives the idea of Course Delivering on Four Continents [4]. From 1990s, Major topics include the development of capstone design courses, course descriptions, project information, details of industrial involvement, and special aspects of team-oriented design projects. An extensive list of references is provided [5]. Norman L. Fortenberry (2011) explains why the next-generation engineers will need interpersonal and management skills to operate effectively [6]. The lack of practical courses and teaching will materials seriously Hinder the true integration of theory and practice. I Inter-professional courses are also necessary.

\subsection{Professional Skills Training and Competency}

The main goal of the applied baccalaureate is getting a graduate of the full setof knowledge, skills, proficiency in the competencies of the studied areas in order to start work immediately [7]. Typical engineering activity requires several roles including those of the engineer, engineering 
technologist and engineering technician, These roles are defined by their Professional competencies. mastering good professional skills is the basic requirement for engineering graduates competency, Proficient professional skills are the foundation of professional competence, engineers, technologists and technicians are expected to maintain and enhance competency throughout their working skills. There are three main ways to develop professional skills, the curriculum system focuses on skill training and technology transfer, developing to Cultivation of entrepreneurial ability and innovative spirit, practical ability training, and Flexibility, interactiveness Personalization, Creative spirit and creativity. The International Technology and Engineering Educators Association (ITEEA) Formulated, Technological Literacy Standards, Yuan Dong (2020), Calderon et al. (2018), Riemenschneider et al. (2018) studied the integration of project management education mode makes education more reasonable and efficient [8]. To meet the multiple demands of complex, agile and innovative projects in the world of work, engineering graduates need to draw on their own decision-making ability and make informed judgements in various collaborative problem-solving situations [9].

\subsection{Faculty and Staff Resources}

The shortage of "dual-professional" teachers will seriously hinder the professional practice level. Zeitz, Leigh E. (1995) suggest developing a Technology Workshop Series for Faculty and Staff [10]. Anne T. Ottenbreit-Leftwich Studies have indicated that when teachers believe technology uses are valuable, they are more likely to incorporate those uses into their practices [11]. Therefore, the transformation of teachers' research results including patents into industrial products is very important to improve teachers' professional quality. University-Industry Cooperation in the Education Domain can Foster Competitiveness and Professional Development [12], Including teacher-Industry Collaboration. Popular indicators for measuring university-industry cooperation are the number and amount of patents or licences, but these do not express the knowledge transfer and university-industry cooperation most adequately, as the collaboration and knowledge transfer also takes place through other types of cooperation [13]. The Transformation of Knowledge and Achievements Is an Important Factor That Encourages Teachers to Continue to Innovate.

\subsection{Employer Cooperation}

Abraham Flexner said that Universities cannot be far away from society, but they are not a weather vane and cannot cater to the popular needs of society. Universities should meet social needs instead of their desires from time to time [14]. Almost all Accreditation standards of applied professionals in the world regard employer satisfaction rate as one of the training goals. In U.S.A, College and University Professional Association for Human Resources (CUPA-HR) conducts annual surveys on the income changes and job changes of graduates of various majors across the country by race, ethnicity, and gender. Closer ties with the regional labor market, For example, In France, over 110 schools elect the employer as the chairman of the board of directors. This effectively guarantees the decision-making power of the labor market in the process of making policies, planning strategies, and professional development for PHE institutions. PHE's course content fully takes into account the current practice background and the needs of the future regional labor market. The academic community and stakeholders (especially the labor market) cooperate through various forms such as curriculum committees, graduation thesis evaluation committees, and professional associations. Development. Among them, in the curriculum committee and graduation thesis evaluation committee, generally at least $50 \%$ of the members come from the labor market. In order to further understand market needs, promote school-enterprise cooperation, and promote regional economic development, local governments usually cooperate with PHE institutions to carry out joint projects. For example, the Plataforma 21 Alto Alentejo project carried out by Portugal's Portalegre Polytechnic Institute (IPP) and the regional government. This project provides a platform for discussion and summarizes the suggestions of different stakeholders on regional economic development. On this basis, IPP Assist the region to formulate sustainable development planning strategies and cultivate relevant professional talents required by the region. On the one hand, it is conducive to the university to grasp the development trend of graduates and facilitate the purposeful reform for the student training model. On the other hand, it also provides guidance or early warning for future graduates' employment based on this information. Annikki Jarvinen \& Viljo Kohonen. 2011 think that Control devices for external factors (region, composition of the evaluation team, etc.) must be prepared to maintain the consistency of evaluation scores [15]. Kichan Yoon, Gyubeom Park, and Munjae Lee analyzes the internal consistency and validity of evaluation indexes based on the results of social service quality evaluation (QE) of a applied programme [16]. Many recent educational innovations all over the world aim to foster active, self-regulated and collaborative ways of learning, since research suggests that these ways of learning are most beneficial in terms of both the quality of learning and the preparation for lifelong learning. Examples of teaching-learning models or pedagogies with this aim include problem-based learning, project-centred learning, competency-based teaching, and concern-based teaching and learning.

\section{Conclusion}

\subsection{The Index System Embodies the Student-Centered and Pragmatic Educational Concepts}

This study explores the quality evaluation index of professional bachelor programmes. Embody the idea about Student-centred teaching methods of Dewey. Even Pragmatic view of education, Colleges or universities must be seen as the epitome of society, and students must learn both in actual 
work and in academic courses. Colleges or universities must be seen as the epitome of society, and students must learn both in actual work and in academic courses. Teaching is not only the responsibility of the professor, but also the responsibility of relevant school staff and relevant social institutions.

\subsection{Lack of Technology and Engineering Curriculum Guides}

Lack of implementation of engineering technical skill standards. ITEEA (International technology and engineering educators association) has tracked the status of technology education in the United States in four separate studies over the past two decades, in 2007, Nineteen state supervisors indicated that their state had technology and engineering curriculum guides, and 22 said that they did not [17]. Development of a unified standard is one of the key factors to improve the quality of the Professional.

\subsection{Strengthen School-Enterprise Cooperation and Jointly Cultivate Talents}

School-enterprise cooperation actively strengthens the relationship between different majors and related companies. According to the overall requirements of each major's training program, the needs of enterprise development and the requirements of employment, in the process of setting teaching standards and revising the talent training program, give full play to the advantages of the enterprise and jointly cultivate with the enterprise.

\subsection{Expand the Team of "Dual-Professional" Teachers and Enhance Teachers' Professional Practical Ability}

The shortage of "dual-professional" teachers will seriously hinder the professional practice level. The insufficient number of "dual-qualified" teachers in applied undergraduate colleges, poor quality, difficulty in introduction, and lack of training is a "magic curse" that perplexes the integration of theory and practice. To this end, applied undergraduates must actively introduce full-time and part-time teachers through multiple channels on the one hand, and on the other hand vigorously carry out the training of "double-qualified" teachers and encourage teachers to exercise in enterprises.

\section{Acknowledgements}

This article is in the Teaching research for the ministry of education humanities and social science plan project in 2017: "The international comparative study of applied science and engineering professional evaluation standards of applied undergraduate colleges and universities" No. 17 yja880070, and Jiangsu province education planning key projects "applied undergraduate colleges and universities of science and engineering applied professional construction and evaluation standard research in international comparison horizon," No. B - a /2016/01/04.

\section{References}

[1] Kim, Yun-Jeong; Kim, Min-Jung; Choi, Hye-Kyong. Study on the Improvement of Quality Evaluation Index for Community Social Service Investment: With a Focus on Fuzzy Analysis on Quality Evaluation Index. International Information Institute (Tokyo). Information; Koganei Vol. 20, Iss. 5B, (May 2017): 3479-3488.

[2] Bernd Wächter, Maria Kelo, Et al. university quality indicators: a critical assessment. 2015, pp: 23-49.

[3] National Research Council. Discipline-Based Education Research: Understanding and Improving Learning in Undergraduate Science and Engineering. pp: 1-2.

[4] Bourner, Tom, Ed.; Katz, Tim, Ed.; Watson, David, Ed. New Directions in Professional Higher Education. Open University Press, 2000.

[5] Alan J. Dutson, Robert H. Todd, Spencer P. Magleby, Carl D. Sorensen'study. A Review of Literature on Teaching Engineering Design Through Project-Oriented Capstone Courses. The reseach Journal for Engineering Education, 02 January 2013, Volume 86, Issue 1, January 1997, pp: 17-28.

[6] Norman L. Fortenberry. Teaching the Practical Skills. Mechanical Engineering. Dec 2011, 133 (12): 36-40.

[7] Elmira Robertovna Khairullina, Et al. Features of the Programs Applied Bachelor Degree in Secondary and Higher Vocational Education, Asian Social Science; Vol. 11, No. 4; 2015, pp: 214.

[8] Yuan Dong. Construction of Educational Quality Evaluation Index System Based on Project Management. International Journal of Information Systems in the Service Sector (IJISSS) 202012 (2), pp: 11

[9] Abbas Mehrabi Boshrabadi \& M. Reza Hosseini. Designing collaborative problem solving assessment tasks in engineering: an evaluative judgement perspective, Assessment \& Evaluation in Higher Education, 26 Oct 2020, pp: 913-927.

[10] Zeitz, Leigh E. Developing a Technology Workshop Series for Your Faculty and Staff. Computing Teacher, v22 n7, Apr 1995, pp: 62-64.

[11] Anne T. Ottenbreit-Leftwicha Krista D. Glazewskib Timothy J. New by Peggy A. Ertmer. Teacher value beliefs associated with using technology: Addressing professional and student needs. Computers \& Education Volume 55, Issue 3, November 2010, Pages 1321-1335.

[12] Ana Afonso, Juan J. Ramírez etc. University-Industry Cooperation in the Education Domain to Foster Competitiveness and Employment. Procedia - Social and Behavioral Sciences, Volume 46, 2012, Pages 3947-3953.

[13] Alo Lilles. Indicators Measuring University-Industry Cooperation, Discussions on Estonian Economic Policy, Vol. 20, Issue 1, p. 204, January 2012.

[14] Abraham Flexner. Universities: American, Englishi, German. Routledge. July in 1994, pp: 3-6.

[15] Annikki Jarvinen \& Viljo Kohonen. Promoting. Professional Development in Higher Education through Portfolio Assessment. 10 Feb 2011, pp: 25-36. 
[16] Kichan Yoon, Gyubeom Park, and Munjae Lee. How Should the Social Service Quality Evaluation in South Korea Be Verified? Focusing on Community Care Services. Healthcare 2020, 8 (3), pp: 294.
[17] Johnny J Moye, William E. Dugger, Jr., DTE, and Kendall N. Starkweather, DTE. The Status of Technology and Engineering Education in the United States: A Fourth Report ofthe Findings from the States (2011-12), May/June 2012, pp: 25-30. 